\section{Восточное приграничье России: альтернативы сельского развития 1}

3.И. КАЛУГИНА, доктор социологических наук. E-mail: zima@ieie.nsc.ru О.П. ФАДЕЕВА, кандидат социологических наук, Институт экономики и организации промышленного производства СО РАН, Новосибирск.

E-mail: fadeeva_ol@mail.ru

В статье рассматриваются возможности социально-экономического развития восточных приграничных регионов России за счет вовлечения в хозяйственный оборот неиспользуемых земель сельхозназначения. На примере отдельных регионов анализируются возможности и ограничения экономической и социально-культурной интеграции с соседними странами. В качестве одного из главных драйверов развития села предлагается использовать уже существующие точки активности местного, в том числе неформального предпринимательства. Рассмотрены контуры государственной политики, которая бы помогла создать благоприятный бизнес-климат в приграничных территориях, а также способствовать их интеграции с другими регионами России и приграничными районами сопредельных стран.

Ключевые слова: приграничные территории, сельское развитие, земельные ресурсы, экономический и человеческий потенциал

Масштабные проекты, обсуждаемые в контексте «восточного вектора» развития России, как правило, нацелены на освоение крупных месторождений полезных ископаемых и создание транспортной инфраструктуры для экспорта сырья в страны Азиатско-Тихоокеанского региона. В случае реализации подобные проекты лишь в малой степени будут способствовать экономическому и социальному прогрессу восточных территорий, так как в существующей системе взаимоотношений федерального центра, крупных ресурсных корпораций и регионов значительная часть полученных эффектов достанется «экстерриториальным» бенефициарам [1]. Но потенциал развития восточных районов не ограничивается интересными для крупных игроков проектами освоения минерально-сырьевых ресурсов. Существенным фактором экономического роста восточных регионов может

${ }^{1}$ Результаты исследований, представленные в данной работе, получень в рамкахпроекта № 0325-2015-0012 «Социально-экономические и ресурсные аспекты трансграничного сотрудничества приграничных территорий Сибири» Подпрограммы III.2П.1. Комплексной программы фундаментальных исследований СО РАН № III.2П. «Интеграция и развитие» на 2015 г. стать развитие сельского хозяйства и связанных с ним отраслей. Основание для такого предположения - наличие больших массивов неиспользуемых или используемых неэффективно земель.

\section{Потенциал развития сельского хозяйства}

Проекты повышения интенсивности использования земельных ресурсов требуют значительных инвестиций, сопоставимых с затратами на освоение новых сырьевых районов. В связи с этим обсуждаются разные стратегии привлечения потенциальных инвесторов, в том числе иностранных. Очевидно, что без участия государства ни одна из таких стратегий не может быть реализована в полной мере. Поэтому важно правильно расставить приоритеты государственной политики развития сельских территорий и определить критерии успешности таких проектов, учитывающие не только глобальные, но и локальные интересы, в том числе интересы людей, проживающих на этих землях. Особую важность представляют развитие приграничных районов и использование возможностей трансграничного сотрудничества в аграрной сфере.

В России, на долю которой приходится более 10\% площади мировых сельхозугодий, на данный момент имеются возможности как для экстенсивного (рост площадей), так и для интенсивного (повышение продуктивности) развития сельского хозяйства На каждого россиянина приходится 12 га земли, в то время как на жителя Западной Европы - 1 га, Азии - 1,1, Африки - 6,4 Северной Америки - 6,1, Южной Америки - 7,3, Австралии и Океании - 37 га [2]. По оценкам специалистов, Россия занимает одно из самых высоких мест в мире по трем ключевым параметрам: общая площадь пашни; распаханность территории (страна принадлежит к числу наименее распаханных); обеспеченность пашней на душу населения (табл. 1). С этих позиций Россия рассматривается как потенциальный поставщик экологически чистых продуктов питания, а также сырья для производства биотоплива

Восточные территории России, включающие в себя регионы Сибирского и Дальневосточного федеральных округов, обладают $42 \%$ сельскохозяйственных земель страны, в том числе $22 \%$ пашни. Однако, как видно из таблицы 2 , степень использования земельных ресурсов, особенно в Сибирском федеральном округе, катастрофически низка. Регионы западносибирского приграничья (Омская и Новосибирская области, Алтайский край), которые имеют общую границу с Казахстаном, принадлежат к числу 
наиболее развитых в сельскохозяйственном отношении сибирских территорий, но даже здесь площади необрабатываемой земли велики. Особенно тревожная ситуация в Алтайском крае главной житнице Сибири и Дальнего Востока

Таблица 1. Страны - лидеры по площади пашни

\begin{tabular}{|l|c|c|c|c|}
\hline Страна & $\begin{array}{c}\text { Площадь пашни, } \\
\text { млн га }\end{array}$ & $\begin{array}{c}\text { Доля пашни, \% } \\
\text { от всей площади } \\
\text { страны }\end{array}$ & $\begin{array}{c}\text { Доля страны } \\
\text { в общемировой } \\
\text { площади пашни, \% }\end{array}$ & $\begin{array}{c}\text { Обеспеченность } \\
\text { пашней, га на душу } \\
\text { населения }\end{array}$ \\
\hline США & 185,7 & 20,3 & 13,8 & 0,62 \\
\hline Индия & 166,1 & 55,9 & 12,3 & 0,17 \\
\hline Россия & 130,3 & 7,7 & 9,7 & 0,92 \\
\hline Китай & 92,5 & 9,9 & 6,9 & 0,08 \\
\hline Канада & 43,2 & 4,9 & 3,4 & 1,44 \\
\hline
\end{tabular}

Источник: [2].

Таблица 2. Использование земель сельскохозяйственного назначения в приграничных регионах Сибири и Дальнего Востока (на 01.01.2014)

\begin{tabular}{|c|c|c|c|c|}
\hline $\begin{array}{l}\text { Территория, } \\
\text { субъект РФ }\end{array}$ & $\begin{array}{c}\text { Площадь земель } \\
\text { сельхозназначения, } \\
\text { тыс. га }\end{array}$ & $\begin{array}{c}\text { Доля } \\
\text { пашни, } \\
\%\end{array}$ & $\begin{array}{c}\text { Доля неисполь- } \\
\text { зуемых земель } \\
\text { сельхозназначе- } \\
\text { ния, \% }\end{array}$ & $\begin{array}{l}\text { Доля неисполь- } \\
\text { зуемой пашни, \% }\end{array}$ \\
\hline $\mathrm{P \Phi}$ & 386465 & 30 & 26 & 18 \\
\hline СФО & 97611 & 24 & 57 & 20 \\
\hline ДФ0 & 65660 & 4 & 4 & 26 \\
\hline \multicolumn{5}{|c|}{ Западносибирское приграничье } \\
\hline Алтайский край & 11535 & 56 & 44 & н.д. \\
\hline Новосибирская обл. & 11150 & 32 & 24 & 16 \\
\hline Омская обл. & 8083 & 50 & н. д. & 13 \\
\hline \multicolumn{5}{|c|}{ Восточносибирское приграничье } \\
\hline Забайкальский край & 8003 & 5 & 13 & н.д. \\
\hline Респ. Тыва & 3368 & 4 & 62 & 76 \\
\hline Респ. Бурятия & 2760 & 25 & 42 & 63 \\
\hline Респ. Алтай & 2620 & 5 & 73 & 27 \\
\hline \multicolumn{5}{|c|}{ Дальневосточное приграничье } \\
\hline Амурская обл. & 3551 & 42 & 56 & 36 \\
\hline Приморский край & 1875 & 37 & 18 & н.Д. \\
\hline Хабаровский край & 375 & 20 & 60 & 37 \\
\hline Еврейская АО & 362 & 25 & 8 & 55 \\
\hline
\end{tabular}

Источник: данные Доклада о состоянии и использовании земель сельскохозяйственного назначения. - М.: ФГБНУ «РосинформагротеХ», 2014 - С.151 $155-156,166-169$.
Земли восточносибирского приграничья, где проходит граница между Россией, Монголией и Китаем, менее пригодны для выращивания зерновых культур, но при этом они обладают высоким потенциалом для животноводства, в первую очередь пастбищного. Но вместо роста поголовья крупного рогатого скота, овец, коз, лошадей, для выпаса которых на территории имеются все условия, в этих регионах увеличивается доля заброшенных угодий и залежей, что грозит утратой этих земель в качестве производительной силы. Подобные процессы запустения характерны для некогда активно используемых территорий Забайкальского края, где за 25 последних лет почти на порядок сократилось поголовье овец (с 4 млн до 500 тыс.), практически прекратилось производство собственной молочной продукции, в 10 раз уменьшились площади обрабатываемой земли [3]. В республиках Тыва, Бурятия и Алтай показатели неиспользуемых земель чрезвычайно высоки, что свидетельствует об аналогичном сжатии ареалов хозяйственного использования этих территорий в постсоветский период. На Дальнем Востоке процессы деградации сельскохозяйственных земель в большей мере затронули Амурскую область, обладающую наиболее значимыми земельными богатствами.

\section{Эффективность сельского хозяйства на восточных рубежах}

Проведенный типологический анализ социально-экономического развития сельских регионов России показал, что большая часть приграничных восточных территорий России - Еврейская автономная область, Забайкальский, Камчатский, Приморский и Хабаровский края, а также республики Алтай, Бурятия и Тыва вошли в отдельный кластер [4]. В этом кластере сельских регионов России производится менее $10 \%$ всей сельскохозяйственной продукции страны, производство животноводческой продукции нерентабельно, очень низкие надои молока (2778 кг против 5867 кг в Краснодарском крае и 5020 кг - в других регионах лидерах в расчете на одну корову). При этом около $80 \%$ производимой аграрной продукции в совокупности дают хозяйства населения и фермерские. На сектор сельскохозяйственных организаций приходится только пятая часть производства, почти треть организаций убыточны. Объем привлекаемых в аграрную 
отрасль инвестиций крайне низок - в 2012 г. инвестиции в основной капитал в расчете на один регион кластера составили 550 млн руб., что почти в 40 раз меньше аналогичных показателей Краснодарского края.

Понятно, что при таком режиме функционирования и финансирования сельского хозяйства быстро переломить процесс длительной деградации невозможно. Отрасль нуждается в ускоренной модернизации, переходе на высокотехнологичные производства в растениеводстве и животноводстве, которые бы позволили преодолеть дефицит рабочих рук, поднять производительность труда и усилить позиции сельхозпроизводителей не только на внутренних, но и на внешних продовольственных рынках. Однако выбор конкретных механизмов развития сельских территорий восточного приграничья важно осуществлять с оглядкой на уже имеющийся не всегда позитивный опыт интеграции других направлений хозяйственной деятельности, осуществляемой в этих регионах, в мировое экономическое пространство.

Слабость местных производителей обусловлена не столько природными, сколько социально-демографическими [5] и политическими факторами, в частности, изъянами государственного управления, допускающего превращение этих территорий в поставщиков необработанного сырья для сопредельных стран. Остро стоит проблема сокращения населения за Уралом - в 2013 г. коэффициент миграционных потерь населения в расчете на 10 тыс. человек в Республике Алтай составил -35 , в Бурятии -37 , в Тыве -10 . Миграционный отток наблюдался и в других восточных приграничных областях: в Алтайском крае -27 , в Забайкальском крае -78. Наименьшим оно оказалось на Чукотке -7 и в Омской области -14 . Из приграничных восточных регионов только в Новосибирской области наблюдался миграционный прирост населения (+73) [6. С. 60]. Длящийся уже несколько десятилетий исход жителей регионов Сибири и Дальнего Востока стал результатом упрощения или «опустынивания» локальных экономических ландшафтов. Поэтому даже в условиях «инвестиционного бума» отсутствие необходимого количества рабочих рук может стать серьезным препятствием на пути реализации амбициозных проектов и заставит власти и инвесторов вспомнить советский опыт мобилизаций в духе «комсомольских строек». Однако на этот раз только мотивация «длинного рубля» может сработать на довольно ограниченный срок: закрепить людей в сельской местности без кардинального улучшения бытовых условий их жизни уже не удастся.

Ярким примером недальновидности внешней политики для районов Сибири и Дальнего Востока является характер лесохозяйственной деятельности. Богатство лесных ресурсов и близость к границе с Китаем, предъявляющим высокий и постоянно растущий спрос на древесное сырье, в условиях некачественного государственного управления стали причиной хищнического истребления природного капитала лесных экосистем восточных регионов страны, однако это не принесло данным регионам заметных экономических выгод [7. С. 35]. Подобная угроза может нависнуть и над сельскохозяйственными угодьями этих регионов, если их использование будет осуществляться бесконтрольно, без соблюдения экологических нормативов, а производимая сельхозпродукция станет дешевым сырьем для производства промышленных товаров и продовольствия на территории соседних стран.

Именно по этому сценарию пока развиваются события в Забайкальском крае, где мы побывали в 2013 г. в социологической экспедиции [3]. Попытки восстановления на приграничных землях Забайкалья племенного животноводства, в том числе овцеводства, оказались не совсем удачными потому, что регион испытывает дефицит перерабатывающих мощностей. В результате мясо и шерсть по низким закупочным ценам уходят заготовителям из других регионов России и Китая, что и определяет низкую рентабельность местного аграрного бизнеса и его сильную зависимость от внешнего спроса.

Более гибкими оказались семейные подворья, которые массово занялись «стихийным» животноводством без регистрации предпринимательской деятельности, используя брошенные пастбища и сенокосные угодья. Налаженные сети закупок «дворовой» говядины, свинины, баранины, за которой приезжают многочисленные предприниматели из самых разных мест, позволяют сельчанам, не покинувшим родные места в поисках лучшей доли, иметь хоть какой-то доход и не на все $100 \%$ зависеть от занятости в крупных сельхозпредприятиях, число которых за последние годы сократилось в разы. Местные власти такое положение дел вполне устраивает, поскольку 
хоть как-то сохраняется социальный контроль за территорией, а приграничным районам не грозит полное обезлюживание.

Также на территории края действуют совместные российско-китайские предприятия, правда, в сельском хозяйстве число легальных организаций ограничено. Значительные площади свободных земель в Забайкалье, да и в других восточных регионах способствуют теневой экспансии китайских тепличных хозяйств, деятельность которых закрыта для российских контролирующих органов. Выращиваемые в «разборных» и весьма экономичных (с точки зрения эксплуатационных расходов) теплицах овощи попадают на рынки больших и малых поселений, а низкие цены делают их доступными для всех. Хорошая урожайность тепличных культур, прежде всего, за счет превышения предельно допустимой концентрации вносимых удобрений, используемых пестицидов и инсектицидов, а также низкие затраты на труд усердных китайских работников делают этот бизнес чрезвычайно доходным [8]. Экологический оппортунизм как характерная черта этого «кочующего» производства, оставляющего после себя сотни или даже тысячи гектаров выжженной химикатами и замусоренной отходами производства земли, способствует формированию у россиян негативного образа китайского фермера, а идеи о передаче неиспользуемых земель в аренду китайским компаниям вызывают в обществе резкое отторжение.

Еще один активно используемый местным населением источник доходов связан с ведением мелкого бизнеса, нацеленного на обслуживание российско-китайского транзита: перевозку туристов и грузов, торговлю, оказание услуг путешественникам в местах пограничного перехода. Но даже в этой сфере первенство принадлежит не российским, а китайским предпринимателям, под чьим контролем открываются кафе и рестораны, строятся гостиницы и другие места для ночлега и стоянки транспорта.

Однако ориентация бизнеса на транзитный поток оборачивается для местных жителей и поселений серьезной проблемой. Быстрая смена контингента проезжающих, которые спешат попасть на китайскую сторону, создает у «привечающих» их на российской стороне предпринимателей соблазн поступиться качеством обслуживания или же свести набор предоставляемых услуг к минимуму. Создавать комфортную среду обитания для проживающих здесь людей бизнес не спешит, полагая, что не сможет конкурировать с имеющейся на китайских приграничных территориях развитой сферой шопинга и разнообразных услуг, в том числе развлекательных и оздоровительных, которыми активно пользуются регулярно пересекающие границу местные жители. В результате российская приграничная территория даже визуально выглядит неухоженной и плохо обустроенной.

Симптомом «болезни транзитно-пропускных мест» служит нежелание предпринимателей инвестировать свой капитал в долговременные проекты, в частности в развитие социальнобытовой инфраструктуры. Попытки местных властей привлечь китайский капитал для строительства жилья и других объектов натолкнулись на выдвинутый китайской стороной ультиматум: обязательное финансовое соучастие российской стороны в этих проектах и преференции в выделении участков для строительства и подключении к сетям инженерно-технического обеспечения, а также повышение квоты для трудоустройства китайских работников. Выполнение в полной мере этих требований оказалось затруднительно на уровне отдельных поселений и целых районов края, в том числе из-за недостаточных полномочий местных органов власти. В итоге и российские, и китайские предприниматели не склонны надолго связывать свой бизнес с этими территориями: их задача - быстро окупить и преумножить свои вложения, в основном в сфере пограничной торговли, а заработанный капитал инвестировать в другом месте, в том числе в КНР.

\section{Социально-экономические перспективы}

\section{сельских восточных регионов}

Меры по преодолению социальной апатии и перелому негативных тенденций в экономике приграничных регионов Сибири и Дальнего Востока, в том числе в части вовлечения необрабатываемых земель Сибири и Дальнего Востока в хозяйственный оборот, в последнее время принято рассматривать в рамках нескольких альтернативных сценариев. В качестве драйверов ускоренного развития аграрно-продовольственного комплекса восточных территорий называются иностранные и/ или отечественные инвесторы в лице крупных (холдинговых) компаний, которые готовы вложить значительные средства в новые производства при предоставлении им определенной системы 
льгот и гарантий. Примерами этих альтернатив могут служить недавно озвученные и сходные по финансовым параметрам намерения китайской Чжэцзянской инвестиционной компанией «Хуаэ Синбан» и российского агрохолдинга «Русагро»², нацеленные на реализацию крупных инвестиционных проектов в Забайкальском и Приморском краях.

Способы предоставления иностранным инвесторам незанятых земельных массивов для организации сельскохозяйственного производства жителями приграничных территорий воспринимаются неоднозначно - они провоцируют общественные дискуссии, в которых превалируют негативные оценки. В 2015 г. упомянутая китайская компания обратилась к правительству Забайкальского края с предложением о передаче совместному предприятию с ее участием в аренду на 49 лет 115 тыс. га пахотных и пастбищных земель, расположенных на территории пяти районов края (с приростом банка земли еще на 200 тыс. га с 2019 г.). Декларированная цель - создание хозяйств животноводческой и птицеводческой специализации, имеющих собственную кормовую базу, а также развитие фармакологического бизнеса, базирующегося на использовании местных лечебных трав.

Как только готовящаяся сделка стала достоянием общественности, несогласие с ней выразили и простые граждане, и депутаты Госдумы. Мотивировалось оно тем, что в итоге эти земли окончательно отойдут китайским гражданам, а у российских властей не будет достаточных рычагов для контроля за условиями землепользования. Хотя в России иностранцам законодательно запрещено напрямую владеть землей и даже ее арендовать, это положение легко обходится с помощью создания совместных предприятий или дочерних компаний, представляющих интересы иностранных бенефициаров. При этом выявить реальных владельцев или арендаторов земли по базам Росреестра чрезвычайно сложно. По оценкам Министерства сельского хозяйства России,

${ }^{2}$ «Русагро» входит в тройку лидеров российских производителей и переработчиков сахарной свеклы, является крупнейшим производителем свинины и зерновых культур. Обрабатывает около 460 тыс. га земли преимущественно в Белгородской, Тамбовской и Воронежской областях. URL: http://www.rusagrogroup.ru/index.php?id=16\&L=1 (дата обращения: 28.09.2015 в собственности и аренде у иностранцев находится 12 млн га российских сельхозугодий [9]. Первое место по величине контролируемых иностранной компанией российских земель занимает казахстанский холдинг «Иволга», в чьем распоряжении находятся 550000 га угодий в Курской, Оренбургской, Челябинской областях [10].

В связи с неоднозначной реакцией на предложение китайцев об аренде земель Забайкалья, которую общественное мнение расценило как угрозу утраты российского суверенитета на этих территориях, Министерство сельского хозяйства РФ начало спешно готовить поправки в Закон об обороте сельскохозяйственных земель, направленные на ужесточение контроля за использованием земель совместными предприятиями и предусматривающие резкое сокращение максимальных сроков аренды с 49 до 10 лет [9]. Однако подобные меры вряд ли будут способствовать развитию сельского хозяйства и привлечению желающих взять в обработку пустующие земли Забайкалья. Именно поэтому региональные власти и пошли на подписание протокола о намерениях с китайской компанией. Губернатор края К.К. Ильковский ясно дал понять, что лучше отдать в обработку земли китайцам и их российским партнерам, чем дальше бороться со степными пожарами, возникающими на неиспользуемых пастбищах, мириться с зарастанием земли кустарником и лесом или же разрушением плодородного слоя ветровой и водной эрозией. Этот договор позволит привлечь в экономику края в первые 5-7 лет 24 млрд руб., создаст новые рабочие места, увеличит налогооблагаемую базу, обеспечит производство востребованной продукции. Со своей стороны власти заверили общественность в том, что интересы российских партнеров и местного населения будут защищены, а агротехнический контроль за производством будет жестким [11]

Подобные подходы должны лечь в основу оценки всех проектов, касающихся российско-китайской интеграции, особенно в контексте плана правительства КНР по восстановлению древнего трансконтинентального коридора. Создание экономического пояса вокруг Нового Шелкового пути затронет восточные территории России. Вместе с тем отсутствие единых социально-экологические стандартов, признаваемых по обе стороны границы, вызывает у специалистов справедливые опасения относительно 
соблюдения безопасных режимов природопользования при реализации совместных проектов и адекватного учета всех последствий нового партнерства [12].

Отечественный вариант подъема экономики в восточных регионах подразумевает создание специальных территорий (опережающего развития) и предоставление комплекса преференций российским компаниям, решившимся взять на себя часть рисков при развитии бизнеса на территориях нового хозяйственного освоения. Именно к числу таких проектов можно отнести объявленное компанией «Русагро» создание в двух районах Приморского края вертикально интегрированного кластера, включающего три направления - развитие растениеводства (приоритет отдается выращиванию сои и кукурузы), свиноводства и переработки сои. В эти проекты холдинг планирует инвестировать 25 млрд руб. Для развития первого направления компания хотела бы увеличить земельный банк (как минимум до 120 тыс. га), чтобы обеспечить комбикормами свиноводческий комплекс с планируемой годовой мощностью производства в 100 тыс. т свинины. Строительство первой очереди комплекса начинается осенью 2015 г.

Руководство компании не скрывает, что этот «восточный разворот» в силу отсутствия крупных конкурентов и возможности поставок на рынок Китая экологически чистой свинины из России может стать весьма выгодным шагом, тем более что половина инвестиционных средств предоставляется компании на льготных условиях по линии государственного проектного финансирования. Самыми серьезными рисками для реализации проекта топ-менеджеры «Русагро» считают нехватку кадров рабочих специальностей, а также проблему хищений продукции. Чтобы решить первую проблему, компания собирается привлечь извне большое количество рабочих рук (в том числе иностранных) и закрепить их в местах размещения производства. Холдинг намерен строить для своих сотрудников ведомственное жилье и вкладывать серьезные средства в развитие социальной инфраструктуры [13].

Два крупных проекта, приведенных в качестве примеров, схожи между собой тем, что в обоих случаях речь идет о весьма локальных, хотя и масштабных замыслах, спущенных «сверху». Они имеют точечный характер и не в силах обеспечить комплексное развитие всех заброшенных территорий. Решение этой задачи, на взгляд авторов, надо искать «снизу» и прежде всего через развитие малого и среднего бизнеса, часто невидимого государственным органам, но уже существующего на территориях в виде семейных ферм, народных промыслов, сферь обслуживания. Этот бизнес нуждается в расширении ниши для сбыта и переработки своей продукции, в техническом обновлении и доступных заемных средствах. Возможно, такую поддержку сможет обеспечить вновь созданная на федеральном уровне корпорация развития малого и среднего бизнеса, если ей удастся организовать свою работу непосредственно в регионах и найти механизмы честного отбора проектов-драйверов. В этом же направлении могут работать практики квотирования в рамках государственных заказов продукции местных производителей для поставки в бюджетные организации, государственного возмещения расходов на приведение брошенной земли в состояние, пригодное для производства сельхозпродукции. Очень важно, чтобы активную позицию в создании благоприятного бизнес-климата занимали местные и региональные органы власти, которые могли бы не только стимулировать претворение в жизнь местных инициатив, но и участвовать в проектировании и осуществлении международных трансграничных форм сотрудничества.

Проведение государственной политики, стимулирующей инициативу снизу, дает шанс в течение ближайших 5-10 лет существенно изменить ситуацию и перейти на новую стадию эволюции экономического и социально-культурного взаимодействия на приграничных территориях. В этом случае, если применить классификацию, предложенную О. Мартинесом [14], можно будет говорить о переходе этих территорий во взаимоотношениях с соседями на качественно иные уровни: от стадий «отчуждения» и «сосуществования» к стадии «взаимозависимых», а в дальнейшем - и «интегрирующихся» территориальных сообществ.

\section{Литература}

1. Нефёдкин В.И. «Бюджетное проклятие» ресурсных регионов ЭКО. - 2015. - № 6. - С. 5-24.

2. Дегтярев К. Земельные ресурсы России - структура и мировое значение. URL: http://old.rgo.ru/2010/07/zemelnye-resursy-rossii\%E2\% 80\%93-struktura-i-mirovoe-znachenie/ (дата обращения 16.09.2015). 
3. Фадеева О.П. Приграничные сельские территории Забайкалья: развитие или деградация? (заметки социолога) // ЭКО. - 2014. № $11 .-$ C. 36-54.

4. Калугина 3. И., Фадеева О. П., Братющенко С. В. Социально-экономическая поляризация сельского пространства России // Регион: экономика и социология - 2015. - № 3 (87). - С. 123-145.

5. Соболева С. В., Григорьев Ю. А., Смирнова Н. Е., Чудаева О. В. Особенности формирования населения приграничных территорий Сибири // ЭКО. - 2014. - № 11. - С. 20-35.

6. Регионы России. Социально-экономические показатели. 2014: Стат. сб. / Росстат. - М., 2014. - 900 с.

7. Природный капитал региона и российско-китайские трансграничные отношения: перспективы и риски / Под ред. И. П. Глазыриной, л. М. Фалейчик. - Чита: Забайкальский государственный университет, 2014. - 526 c.

8. Виноградова П. Скажите спасибо, что мы вас кормим. URL: http:// rusplt.ru/society/skajite-spasibo-chto-myi-vas-kormim-18408.html (дата обращения: 15.09.2015).

9. Кунле М. Русская земля - для россиян // Ведомости. - 2015. 31 авг. URL: www.vedomosti.ru/newspaper/articles/2015/08/30/606807russkaya-zemlya-dlya-rossiyan (дата обращения: 10.09.2015).

10. Крупнейшие владельцы сельскохозяйственной земли в России на 2015 год. URL: www.befl.ru/upload/iblock/491/49149771547af05ede 081aec5f623916.pdf (дата обращения: 07.07.2015).

11. Ильковский К. Мы всех зовем и звали, но пришли китайцы // Известия. - 2015. - 26 июня. URL: izvestia.ru/news/588143 (дата обращения: 13.08.2015)

12. Глазырина И. П., Симонов Е.А. «Экологическая цивилизация» Китая: новые вызовы или новые перспективы для России? // ЭКО. 2015. - № 7. - C. 52-72.

13. Басов М. В растениеводстве идет несколько революций // Ведомости. - 2015. - 30 июня. URL: http://www.vedomosti.ru/business/characters/ 2015/06/30/598583-v-rastenievodstve-idet-neskolko-revolyutsii. (дата обращения 18.07.2015).

14. Martinez O. Border People: Life and Society in U.S. - Mexico Borderlands. Tuscon: University of Arizona Press, 1994. - 352 p. 